\title{
The Renin-Angiotensin System, Hypertension, and SARS-CoV-2 Infection: a Review
}

\author{
Premjith Gathiram $^{1} \cdot$ Irene Mackraj $^{2} \cdot$ Jagidesa Moodley $^{3}$ (D) \\ Accepted: 23 February 2021 / Published online: 25 March 2021 \\ (C) The Author(s), under exclusive licence to Springer Science+Business Media, LLC, part of Springer Nature 2021, corrected publication 2021
}

\begin{abstract}
Purpose of Review This review focuses on the associations between the renin-angiotensin system, hypertension, and severe acute respiratory syndrome (SARS-COV-2) infection. A brief prelude on the current state of affairs with COVID-19 is given. In addition to an overview of ACE2, Ang II, and Ang (1-7), this review presents a brief statement on hypertension, including the function of enzymes involved in the control of hypertension, cardiovascular disease, diabetes mellitus, and other malignancies. Recent Findings There is currently no data in support of the concerns raised with the use of ACEIs/ARBs. Many researchers have voiced concerns that the use of ACEIs and ARBs may increase tissue ACE2 levels. These researchers therefore recommend that individuals on ACEIs/ARB's medications withhold such antihypertensive drugs, unless advised by their physicians to do so.

Summary SARS-CoV-2 uses ACE2 receptors as the port of entry to human hosts. ACE2 and ACE are different enzymes and ACE inhibitors do not inhibit ACE2. Therefore, the use of ARB's or ACEIs should not be discontinued if an individual is infected by SARS-CoV-2. Further studies are required to investigate the effect of ACEIs and ARBs on ACE2 expression and COVID-19.
\end{abstract}

Keywords Renin-angiotensin system $\cdot$ Hypertension $\cdot$ SARS-COV-2 · Angiotensin-converting enzyme inhibitors $\cdot$ Angiotensin II

\section{Introduction}

The causative agent for COVID-19 disease which causes severe acute respiratory syndrome is the coronavirus-2 (SARSCoV-2) [1]. The disease is primarily spread by respiratory droplets [1, 2], perhaps by aerosol spread is also likely [1]. According to the who, it is believed that the virus may be transmitted by aerosol especially in crowded places or during the delivery of a speech [1]. The SARS-CoV-2, like all other coronavirus (SARS-CoV-1 and Middle East Respiratory

This article is part of the Topical Collection on Blood Pressure Monitoring and Management

Jagidesa Moodley

jmog@ukzn.ac.za

1 School of Nursing and Public Health, Department of Family Medicine, University of KwaZulu-Natal, Durban, South Africa

2 School of Laboratory Medicine and Medical Sciences, University of KwaZulu-Natal, Durban, South Africa

3 Department of Obstetrics and Gynecology, Women's Health and HIV Research Group, University of KwaZulu-Natal, Durban, South Africa syndrome (MERS-CoV)), enters the human body and binds to angiotensin-converting enzyme-2 (ACE2) receptors [3, 4]. Angiotensin-Converting Enzyme-2 receptors are expressed in most tissues and organs of the body, but substantial numbers are present in lung parenchymal cells, mainly in type 2 alveolar epithelial cells $[4,5]$.

Most individuals infected with SARS-CoV-2 present with mild clinical manifestations, such as fever, dry cough, myalgia, excessive sputum production, loss of smell, and diarrhea [4, 6-8]. However, the elderly and those with comorbid conditions, such as asthma or respiratory problems, cardiovascular abnormalities, diabetes mellitus, liver and kidney problems, are more likely to have pneumonia, either bilateral or unilateral, as a result of infection of the lower respiratory tract $[6-13,14 \bullet \bullet, 15,16]$.

Reverse-transcriptase polymerase chain reaction (R-T PCR) is recognized as the gold standard for the identification of COVID-19 disease, despite having a low sensitivity compared to chest computerized tomography (CT) scan which in most cases, show positive results of lung infection as indicated by a picture of ground-glass opacities or nodules or bilateral reticular nodular opacities [9-13]. 


\section{Classical Renin-Angiotensin System}

\section{Angiotensin-Converting Enzyme}

The renin-angiotensin-aldosterone system (RAAS) is a master regulator of arterial blood pressure; electrolyte and water balance [14••, 15-18]. New developments in renin-angiotensin system (RAS) have described two different systems of RAS: the classical and the local or tissue RAS [14••, 19]. However, the classical RAS together with aldosterone are chiefly responsible for maintenance of systemic arterial blood pressure and body fluid homeostasis, while the tissue RAS governs the entire activities of the body tissue concerned [14••, 20••]. A drop in arterial pressure activates the release of renin into the circulatory system where it acts on angiotensinogen (formed in the liver) to convert it to angiotensin I (Ang I) [17, 21, 22]. The angiotensin-converting enzyme (ACE) receptors occur in the endothelial cells of the circulatory system $[20 \bullet \bullet, 23 \bullet \bullet$, and the secretion of ACE occurs in the lungs' endothelial cells where it converts Ang I to Ang II [24]. Angiotensin II is a powerful vasoconstrictor causing the blood pressure to rise to normal levels $[14 \bullet \bullet, 20 \bullet \bullet, 23 \bullet \bullet$. However, when the systemic arterial blood pressure is low, it additionally requires homeostatic control of body fluids and electrolyte levels which are the functions of the renal system [25]. The tissue-specific RAS which are found in most body tissues include renin, angiotensinogen, ACE, and ACE inhibitors [19].

\section{ACE2 Receptors, ANG-(1-7), ANG (1-9), and Hypertension}

\section{ACE2, Ang (1-7), and Ang (1-9)}

Donoghue et al. and Tipnis and co-workers independently identified ACE2 receptors but the latter called the same enzyme ACEH. In addition, both research groups have declared that ACE2 and ACEH share a common homology with ACE $[26,27]$. In addition, both research groups have identified that ACE2 or ACEH receptors are located in the heart, kidney, and testes including endothelial cells in these organs [26, 27]. However, Tipnis and co-workers also found moderate levels of ACEH receptors in the ileum, colon, and the ovary [27]. Angiotensin-converting enzyme 2 or ACEH converts Ang I to Ang-(1-9) but ACE is required to convert Ang-(1-9) to the active form of ANG-(1-7). However, ACE2/ACEH can convert Ang II directly into Ang (1-7). The function of Ang (1-7) is to drop blood pressure whenever it rises (by the action of ANG II) back to normal levels (Fig. 1). Both research groups have identified ACE2 as being primarily produced in the heart and kidneys, and indicate that these two organs play a role in the regulation of arterial blood pressure and in the homeostasis of liquid and electrolyte balance [28]. Subsequently, Harmer et al. have observed that ACE2 receptors are present in 72

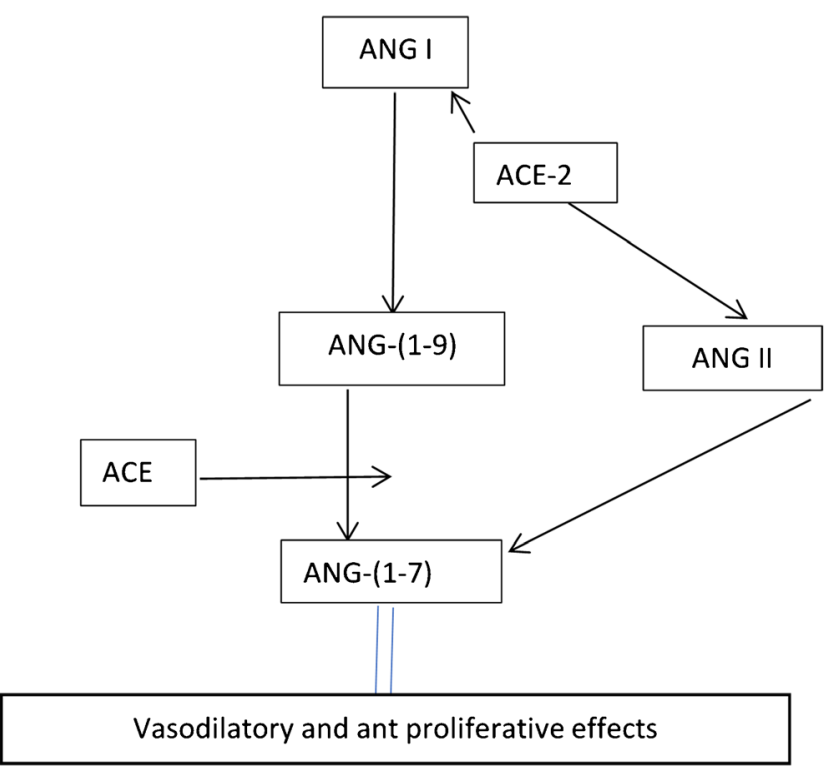

Fig. 1 Action of ACE-2 and ACE on the formation of ANG-(1-7) from ANG I and ANG II

tissues of the body and confirmed that mRNA expression levels were high in the testicular tissues, left ventricle of the heart, the renal systems, and the gastrointestinal system including the ileum, duodenum, jejunum, caecum, and colon. Of the 72 tissues studied, the highest expression levels were observed in the ileum [29]. Additional studies by Li et al. and Hamming et al. localized ACE2 receptors in other tissues, such as the respiratory system [4, 30].

There are two forms of ACE2 receptors: the membrane bound or transmembrane ACE2 which is responsible for the conversion of Ang I or Ang II into Ang (1-9) or Ang (1-7), respectively. However, ACE converts Ang (1-9) into Ang (17) $[31,32]$. Ang1-7 is responsible for causing hypotension or excretion of electrolytes (mainly sodium) and water by the renal system [32]. In addition, ACE2 receptors have binding sites for SARS-CoV-2 as reported by Yan et al. [32]. However, the soluble form of ACE2 is present in the circulatory system and is responsible for binding of SARS-CoV-2 $[32,33]$. Batlle et al. suggest that circulating ACE2 may be used for targeting, modification, detection, or other novel therapeutic and diagnostic applications for treatment or prevention of COVID-19 [33].

The SARS-CoV-2 virus uses ACE2 receptors for cell entry into the human body but physiologically the main function of ACE2 enzyme is for maturation of Ang I or Ang II in blood pressure regulation [3, 32]. Therefore Ang II (as the main octopeptide of RAAS) is not only a very strong vasoconstrictor which raises systemic arterial pressure but also carries out a broad array of physiological and pathological influences by binding to specific broad array of receptors [19, 28]. Among the more well-known studied are Ang II type 1 (AT1) and Ang II type 2 (AT2) G-protein-coupled receptors [28]. The 
AT1 receptors are situated in the vasomotor centers of the brain stem, kidneys, adrenal glands, vascular smooth cells, and in the heart. The ATIR are the main receptors of Ang II, which causes vasoconstriction of the vascular smooth muscles, increasing the total peripheral resistance, excitation of the vasomotor centers to increase the heart rate and cardiac contractility, and increasing salt and water reabsorption by the kidneys, as they are a major site for blood pressure regulation [23••]. The AT1 receptors are antagonists of AT2 receptors, which generally cause blood vessels (arterioles) to dilate, thereby decreasing the arterial blood pressure. However, in normal individuals, the action of ACE on Ang I causes the formation of Ang II, while ACE2 through conversion of Ang II into Ang (1-7) causes hypotension because it is a vasodilator $[14 \bullet \bullet, 26,27,34,35]$. Since the kidneys are the primary blood pressure regulators, Crackover et al. determined ACE2 enzyme levels in the kidneys [23••]. However, ACE2 only has renal effects if the systemic arterial blood pressure rises above normal (brought about by Ang II) or it is below normal levels, which will require absorption of sodium and water by the kidneys.

\section{Hypertension}

Angiotensin-converting enzyme (ACE) and angiotensinconverting enzyme 2 (ACE2) receptors have two opposing effects on blood pressure. While ACE generates Ang II, ACE2 is responsible for hypotensive effects by generating Ang (1-7) which act through Mas receptors found mainly on the blood vessels causing vasodilation. However, hypertension still occurs in some individuals. The main types are primary, the exact cause of which is unknown, and secondary [23••]. However, it is known that primary hypertension is related to lifestyle and genetic factors, and in addition, certain population groups respond to ACEIs/ARBs drugs and other hypertensive medications $[23 \bullet \bullet, 36]$, while other population groups (mainly those of African ancestry) may respond only to diuretics and calcium channel blockers $[36,37]$. Therefore, in individuals with hypertension or diabetes or with cancer, the accepted norm is to prescribe ACEIs, ARBs, calcium channel blockers, diuretics, alpha, or beta-blockers. Figure 2 is a diagram on the control of hypertension, based on the 2020 guidelines of the International Society of Hypertension (ISH) [38].

\section{SARS-CoV-2: Virus Entry into a Given Human Cell}

The SARS-CoV-2 viruses use the ACE2 receptors in the lung parenchyma and in other organs and the cellular protease, TMPRSST, to enter a given cell $[39,40]$. Thus, ACE2 receptors and the protease enzyme TMPRSST are both essential for

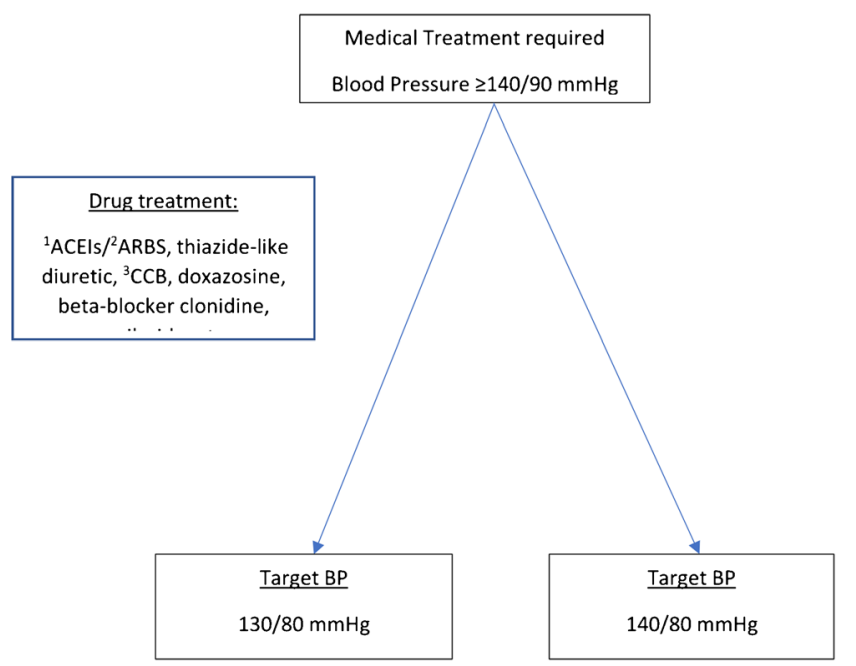

Fig. 2 Treatment of hypertension, cardiovascular diseases, diabetes mellitus, chronic kidney diseases (Guidelines International Society of Hypertension, 2020). ${ }^{1}$ ACEIs-Angiotensin-Converting enzyme inhibitors; ${ }^{2} \mathrm{ARBS}$-Angiotensin II receptor blockers; ${ }^{3} \mathrm{CCB}$ - calcium channel blocker

the viral entry into a given cell [40]. However, there is no direct evidence showing that ACE2 receptors are used for entry into the human body in all COVID-19 patients.

\section{Development of a Vaccine for SARS-CoV-2}

Gurwitz is of the view that the development of a vaccine is time consuming and it may be developed too late for its effective use, because the SARS-CoV-2 virus may have mutated [41]. In addition, Gurwitz states that AT1 receptor blockers ,which do not depend on mutations, should be used as therapeutic agents for reducing the aggressiveness and high mortality of the SARS-CoV-2 virus infection [41].

\section{The Use of ACEls and ARBs in COVID-19 Disease}

\section{Investigations Using Normal Animals Without Being Infected with a Coronavirus}

The most common pharmaceutical drugs used for hypertension, and other cardiovascular diseases (CVDs), are (ACEIs) (such as lisinopril, enalapril) or ARBs (such as losartan). In order to test the effects of using ACEIs and ARBs, Ferrario et al. used the ACEI (lisinopril) or ARB (losartan) in experimental animals (normal rats) and measured, besides other parameters, ACE2 mRNA expression levels in plasma and cardiac muscle tissue. These researchers found that the administration of ACEI or ARB caused an increase in ACE2 mRNA expression levels [42••]. 


\section{Effects of Animal Models on SARS-COV-2 Infection in Humans}

The problems arose when it was realized that SARS-CoV-2 also uses ACE2 receptors to enter host cell/s and if ACEIs/ ARBs were used (for whatever reason), it would mean that viral entry into the cells would increase. Many researchers [16, 39, 40, 43-53], including Sommerstein et al., wrongly believed that the treatment of experimental animals with ACEIs/ARBs causes increased mRNA expression levels of ACE2, which may mean that more viruses would enter the cells with the use of ACEIs or ARBs [54]. However, we take into account that the research by Ferrario et al. was done in normal rats, which were not hypertensive or have CVDs, diabetes mellitus, or malignancies, for which ACEIs or ARBs are commonly used $[42 \bullet \bullet$. According to a few research groups, the publication by Ferrario et al. [42••] invoked the "lay press" and caused concerns and even anxiety among patients and their clinicians $[50,51,54,55]$. Nevertheless, Sommerstein et al. are also of the view that the long-term intake of ACEIs/ARBs would facilitate SARS-CoV-2 entry and replication in host cells; however, currently, these researchers believe the intake of these medications $\mathrm{s}$ by individuals infected with SARS-CoV-2 would be protective and safeguard against pulmonary complications [54]. Sommerstein et al. indicated that they support the position and the joint statements issued by the European and American Societies of Cardiology, who express that ACEIs and ARBs are safe and should be continued as prescribed [54]. Sommerstein et al. also clarified that the research by Ferrario et al. bears no consequences to COVID-19 disease [54].

We observed that some researchers interpreted that the use of ACEI/ARB in COVID-19 disease, and the upregulation ACE2 mRNA expression (using ACEI/ARB) levels found by Ferrario et al. [42••], attributed a protective role that could reduce lung injury by leading away from Ang II (which is responsible for lung injury) to the pathway ACE2-Ang (1-7) $[51,56]$. For the benefit of those who may have missed the point, we wish to reiterate that Ferrario et al. carried out their research in normal rats, which were not hypertensive, or having other cardiac diseases, diabetes mellitus or malignancies, nor were they being treated with either ACEIs or ARBs for any of the said abnormalities. Ferrairio et al. observed that treatment of normal rats with ACEI (lisinopril) caused an increase in cardiac muscle ACE2 mRNA expression levels and use of losartan caused a similar effect in mRNA expression levels $[42 \bullet \cdot]$.

Zhou et al. confirmed that in both SARS-CoV-2 and SARS-CoV, which had caused a similar outbreak in China and other countries during 2002-2003, both used ACE2 receptors to gain entry into human body cells [4, 57]. Importantly, to further correct the perception of many researchers [40] and the lay press, we need to emphasize that
Turner et al. [34], one of the co-workers of Tipnis et al. [27], stated categorically that ACEH/ACE2 is not inhibited by ACE inhibitors. In addition, we are of the view that there is no direct association between ACE and ACE2 receptors, nor is there a direct association between the use of ACEIs and ARBs in SARs-CoV-2 infection. We are also of the view that it is not detrimental to the SARS-CoV-2 patients who were treated with ACEIs/ARBs to continue with their treatment with ACEIs/ARBs unless they experience a drop in their arterial pressure below the accepted normal range, in which case such patients are advised to see a physician or a cardiologist. In addition, we support the statements issued by several global cardiology and hypertension organizations that those who have contracted SARS-CoV-2 infection should continue with their treatments with ACEIs and ARBs medications [58-60].

Regarding tissue expression, a few researchers are of the view that the use of ACEIs/ARBs increases ACE2 levels in the heart and the kidney but not in the lungs [61]. It also believed that the use of ACEIs/ARBs increases ACE2 levels in the brain, heart, and the kidney [61]. It is thought that because ACE2 levels increase by the use of ACEIs/ARBs during COVID-19 disease, it results in cardiac problems [61]. The available literatures on COVID-19 on the continued use of ACEIs/ARBs are of contrasting views. While some researchers are of the view that the use of ACEIs/ARBs does more harm than good to SARS-CoV-2 patients by increasing ACE2 receptor expression levels [61-63], other researchers are of the view that perhaps ACEIs/ARBs should be replaced with calcium channel blockers [62]. However, to switch medication from one (prescribed) to another (not prescribed) is a lengthy process in many countries. We would like to offer an advice of caution to those unsure of ACEI or ARB usage or that they should reflect on the findings of Ferrario et al. on the notion that ACE2 receptors would cause more SARS-CoV-2 binding, as normal rats were used in their findings of the increased mRNA expression levels of ACE2 in cardiac cells. Alexandre et al. were of the view that they would rather wait on the outcome of the clinical trials (Reference Numbers NCT04312009 and NCT04311177), and in the interim follow the position of international societies such as the French Society of Hypertension and the European Society of Cardiology (ESC) and many publications against stopping ACEI/ARB in COVID-19 [48].

Emilsson et al. were prompted by findings of Ferrario et al. [42・•] to investigate ACE2 levels in SARS-CoV-2 patients who received ARBIs/ARBs [64]. These researchers had the following question: "Does treatment with antihypertensive medications angiotensin-converting enzyme inhibitors (ACEIs) and angiotensin II receptor blockers (ARBs) result in elevated levels of cellular receptor for the coronavirus SARS-CoV-2, ACE2?" [64]. In their study, they found that serum levels of ACE2 were unaffected and therefore they concluded that those SARS-CoV-2 patients taking ACEIs or 
ARBs should not discontinue taking these medications [64]. Notably, these investigators measured ACE2 levels in serum, which was the soluble form of ACE2, and ideally should have measured the transmembrane levels of ACE2 levels, which is the form of ACE2 that exists in the tissues. Similarly, Sama et al. [65] measured circulating concentration of ACE2 in men (median age 69 years) and women (median age 75 years) to validate the use of ACEIs/ARBs or mineralocorticoid receptor antagonists (MRAs) in this population cohort. These researchers studied 1123 men and 575 women with heart failure, and they found that ACE2 levels were higher in men compared to women (accounting for the higher death rate in men), and the use of these inhibitors was superior to non-use of the inhibitors/blockers [65].

Guo et al. are of the view that the use of ACEIs/ARBs should continue in spite of upregulated ACE2 because "ACE2 is like a double-edged sword," ACE2 is upregulated when SARS-CoV-2 viruses bind to types 1 and 2 epithelial cells in the lung parenchyma [66]. Furthermore, some researchers believe that the use of ACEs/ARBs results in an increase in ACE2 mRNA expression levels elsewhere in the body [66]. In a separate retrospective study, utilizing 3936 patients with COVID infections, Guo et al. observed that the use of ACEI/ARBs was not associated with severity of the disease but they found that the mortality rate was lower when compared to non-users of the drug [67].

In addition, Busse et al. reported that the use of ACEIs/ ARBs in COVID-19 disease is purely speculative; however, these researchers have decided to support the American College of Cardiology (ACC) and the ESC and both organizations have issued statements advising the continuation of treatment of COVID-19 with ACEIs/ARBs [39]. Likewise, Esler and Esler have a hypothesis that the administration of ACEIs and ARBs to hypertensive patients with COVID-19 disease may be harmful but nevertheless they supported the administration of ACEIs/ARBs to these patients until proven that the use of ACEIs/ARBs are harmful [46]. Battistoni and Volpe also agree with the said statement [47]; however, these researchers felt that the binding of SARS-CoV-2 to ACE2 causes downregulation of ACE2 [47].

We agree with the sentiments expressed by Danser et al. [68]. Many researchers were/are of the view that the ESC recommends that COVID-19 patients, despite being hypertensive, diabetic, or other cardiovascular complications, should continue taking these medications, because currently there is no clinical or scientific evidence available to suggest that ACEIs or ARBs should be discontinued if they are infected with COVID-19. Furthermore, the ACC suggests that should patients afflicted with, for example, heart failure, hypertension, and ischemic heart disease contract COVID-19, then the attending physician should continue with the respective medications, and the final decision to continue or not should depend on the hemodynamic status and clinical presentation of SARS-CoV-2 individual at the time of contracting the virus [40]. Interestingly, Battistoni et al. state that SARS-Cov-2 has higher affinity for ACE2 than SARS-CoV and describe the state of ACE2 in the unbound form or soluble form of ACE2 [47].

\section{Recent Comments/Reviews on the Use of Angiotensin-Converting Enzyme Inhibitors and Angiotensin Receptor Blockers}

Vaduganathan et al. believe that both ACEIs and ARBs are prescribed medications worldwide and as such guidance on the use of these drugs in COVID-19 patients is urgently required; however, they are hopeful that a clinical trial is underway to resolve the anomaly [43]. These authors are also concerned that abrupt withdrawal of RAAS inhibitors may be harmful in certain high-risk or suspected patients with COVID-19 [43]. In addition, they are of the opinion that the use of those RAAS inhibitors should still be continued [43].

Furthermore, any relationship between ACE and ACE2 receptors in the lungs is not confirmed because the ACE2 receptors are found in different cellular types, while the ACE receptors, which are responsible for conversion of ANG I into ANG II, are mainly found in the endothelial cells (mostly in the lungs). The ACE2 receptors occur mainly in type 2 cells in the lung parenchyma.

On the other hand, Patel and Varma believe that there is a strong relationship between ACEI and ARB usage and severity of SARS-CoV-2 infection and mortality in human beings [45]. Their belief is that ACEIs inhibit ACE2, but this is not possible because ACE2 is a carboxypeptidase, and the other concern is that the use of ACEIs and ARBs would increase the expression of ACE2 and thus will allow more viral entry and propagation [45]. However, these researchers also believe that there is even less evidence available to show that treatment of ACEIs and or ARBs can decrease the pulmonary injury caused by SARS-CoV-2. However, they then reiterate the statements made by a number of organizations such as the Council on Hypertension of the European Society of Cardiology, the American Heart Association, the Heart Failure Society of America, and the ACC; advocating that the patients should continue taking ACEIs/ARBs as prescribed until a careful assessment is made. In the meantime, these researchers feel that there is insufficient clinical or scientific evidence available on the management of hypertension in COVID-19 disease [45].

Kai and Kai also believe that administration of ACEIs/ ARBs to SARS-CoV-2 patients could increase the infectivity of the virus, and could also increase the expression of ACE2 in the cardiovascular and renal system, and aggravate the morbidity and mortality of SARS-CoV and the severity of the infection in hypertensive and other CVD patients [69]. 
Pertaining to COVID-19 disease, similar concerns have been raised, including the high mortality rate of COVID-19 in older patients with comorbidities such as hypertension, diabetes mellitus cardiovascular disease, chronic pulmonary disease, and cancer [69]. In addition, individuals have been concerned whether the use of ACEIs and ARBs could have contributed to the high mortality and morbidity rates. These researchers think that proper adjustments have not been made for age and comorbidities and therefore the burden seems to be high. However, these researchers are, nevertheless, of the view that the use of ACEIs/ARBs should not be withheld but should be continued, especially as this is in keeping with a number of relevant International Organizations [69].

Verdecchia et al. [70] have to be acknowledged for providing an excellent review, but these researchers did not consider that prescribing ACEIs/ARBs is mainly to assist the control of hypertension. They may have not factored why primary hypertension occurs and what happens to the so-called ACE2 receptors.

Fang et al. are of the view that ACEIs or ARBs may become a new method of treating COVID-19 patients [71]. Sriram and Insel in a review article concluded that individuals with SARS-CoV-2 on ACEIs/ARBs should continue with this medication [72]. Similarly, other researchers who did not find any significant difference in hypertensive patients who tested positive for COVID-19 disease, viz. between those on either ACEIs or ARBs and hypertensive patients not on either medications, and supported continued ACEIs or ARBs prescriptions [73-75]. However, Mehta et al. and Felice et al. are of the view that a larger sample size should be used to either confirm or refute their opinion $[73,75]$. In addition, according to Kuster et al., neither the withdrawal nor replacement of ACEIs or ARBs in patients with hypertension COVID-19 disease is advisable [51].

\section{Retrospective Studies Showing No Harm in Using ACEls or ARBs in COVID-19}

In a study among individuals with hypertension and COVID19 , Wang et al. tried to determine an association between use of ACEI/ARBs and all-cause mortality [52]. They carried out their study at 9 different hospitals in mainland China among 1128 adult hypertensive patients. For this study, the researchers compared 188 patients on ACEIs/ARBs (ACEIs/ ARBs group) with 198 without using ACEIs/ARBs (nonACEIs/ARBs) group (taking other antihypertensive medications). After adjusting for all covariates, these researchers found that the hypertensive group on ACEIs/ARBs was associated with decreased mortality compared to non-users of ACEIs/ARBs [52].
Recently, Yang et al. observed that hypertensive patients, taking ACEIs or ARBs or without taking these drugs, had a non-significant difference in the death rates between the two groups [76]. Furthermore, in an outpatients study using a large sample size, in the USA, the use of ACEIs/ARBs compared with the use of other hypertensive medications in patients with COVID-19 disease requiring hospitalization. The study found that the use of ACEIs on their own and the use of ARBs alone compared with the use of other medications in individuals with hypertension and COVID-19 did not show the need for hospitalization in outpatients [77]. The second component of the study was to see if there was any association between those taking ACEIs compared to other drugs for hypertension in the inpatient mortality rate. The study found that mortality rate is not associated with the use of ACEIs compared to other antihypertensive drugs [77].

Another group in New York City assessed the risk of previous treatment of ACEIs, ARBs, B-Blockers, calcium channel blockers or thiazide diuretics for hypertension, and the likelihood of testing positive or negative for COVID-19 disease, in addition to contracting a severe (defined as admitted into intensive care, put on a mechanical ventilator, or death) SARs-CoV-2 illness [78]. These researchers observed no substantial increase in the likelihood of testing positive for COVID-19 or the severity of COVID-19 disease among patients treated with antihypertensive medications [78]. In another study in mainland China, on SARS-CoV-2 infected 42 hypertensive patients (ages 55.8-69 years) were divided into two groups: the ACEI/ARB $(n=17)$ and non-ACEI/ARB $(n=25)$ groups. The latter group were treated for antihypertension drugs: calcium channel blockers, $\beta$ Blockers, or diuretics) [79]. No significant differences in blood pressure were noted between the two groups. Furthermore, during hospitalization in the non-ACE/ARB group, 12 patients developed severe hypertension and one patient died, whereas in the ACEI/ARB group, 12 developed severe hypertension and none died [79]. In addition, in the ACEI/ARB group, the risk of developing severe hypertension was higher than in the non-ACEI/ARB group [79]. In the UK, a large study by Bean et al. consisted of 1200 patients with COVID-19 disease in a mixed ethnicity population group. They compared individuals on ACEIs/ARBs (commonly used drugs by hypertensive and diabetic patients) and those not on ACEIs/ARBs [80]. They found that those taking ACEIs/ ARBs were significantly older than those not taking any medication [80]. In an unadjusted logistic regression analysis, these workers found no difference between those who were on ACEIs/ARBs and those not taking these medications [80]. In a retrospective study of 362 hospitalized hypertensive patients with COVID-19 disease, Li et al. investigated 115 patients who were taking ACEIs or ARBs and compared them to those not taking these medications. No differences in severity of the illness and in death rate (survivors vs non-survivors) 
and in complications developed [81]. Another retrospective study by Peng et al., in SARS-CoV-2 hypertensive patients with combined cardiovascular disease (CVD), found that the use of ACEIs/ARBs did not affect the morbidity or mortality [82].

\section{Case Control Study Showing No Harm in Using ACEls/ARBs in COVID-19}

Mancia et al. were one of the few researchers to perform a real case $(n=6272)$ control $(n=10759)$ study in Italy [83]. The two groups were matched according to age, biological sex, and the municipal area of residence. These researchers observed that the use of ACEIs and ARBs was more common among the case group than the control group and case group had a worse clinical profile than the control group because the case group had higher prevalence of cardiovascular diseases [83]. After adjustment for confounders, they found no differences between the two groups [83].

Finally, the Board members and the Director of the Italian Society of Hypertension has made the following direct statement on the use of RAAS Inhibitors (including ACEIs and ARBs) in COVID-19 disease [84]:

iThe experiments were done only on animal models and not on human beings, and to date, there is no evidence that individuals with hypertension are over-represented in COVID-19 disease.

iiThere is no clinical evidence in humans that associates the intake of ACEIs/ARBs with COVID-19 disease.

iiiThere is no clinical evidence in SARS-CoVo-2 coronavirus patients that confirms the harmful effects of ACEIs/ ARBs or protective effects in the context of COVID-19 epidemic [84].

In addition, reiterates the previous statement release that the use of ACEIs and ARBs should not be withdrawn [84].

\section{Conclusion}

In normal individuals, ACE2 is a homolog of ACE and it has hypotensive effects. Entry of SARS-CoV-2 into the cells is by binding to ACE2 receptors. Because ACE and ACE2 are different enzymes ACE, inhibitors do not inhibit ACE2. Further studies are required to investigate if the use of ACEIs or ARBs does not upregulate ACE2 in COVID-19, and in fact, there is no data supporting evidence available the claim that this medications allows more virus entry into the any cell. Therefore, RAS blockers or ACEIs should not be discontinued during COVID infection unless there is a good reason for example when there is a fall in systemic arterial pressure.

\section{Compliance with Ethical Standards}

Conflict of Interest The authors declare that they have no conflicts of interest.

Human and Animal Rights and Informed Consent This article does not contain any studies with human or animal subjects performed by any of the authors.

\section{References}

Papers of particular interest, published recently, have been highlighted as:

•• Of major importance

1. World Health Organization. Clinical management of severe acute respiratory infection when COVID-19 is suspected 2020. Available from: https://www.who.int/publications-detail/clinicalmanagement-of-severe-acute-respiratory-infection-when-novelcoronavirus-(ncov)-infection-is-suspected.

2. Clinical Editor. As we went to press: COVID-19 continues to spread. Am J Nurs. 2020;120(4):15.

3. Li W, Moore MJ, Vasilieva N, Sui J, Wong SK, Berne MA, et al. Angiotensin-converting enzyme 2 is a functional receptor for the SARS coronavirus. Nature. 2003;426(6965):450-4.

4. Li MY, Li L, Zhang Y, Wang XS. Expression of the SARS-CoV-2 cell receptor gene ACE2 in a wide variety of human tissues. Infect Dis Poverty. 2020;9(1):45.

5. Alifano M, Alifano P, Forgez P, Iannelli A. Renin-angiotensin system at the heart of COVID-19 pandemic. Biochimie. 2020;174:30 3.

6. Chen H, Guo J, Wang C, Luo F, Yu X, Zhang W, et al. Clinical characteristics and intrauterine vertical transmission potential of COVID-19 infection in nine pregnant women: a retrospective review of medical records. Lancet. 2020;395(10226):809-15.

7. World Health Organization. Coronavirus 2020 [cited 202018 April]. https://www.who.int/health-topics/coronavirus\#tab=tab 1.

8. Zhu H, Rhee JW, Cheng P, Waliany S, Chang A, Witteles RM, et al. Cardiovascular complications in patients with COVID-19: consequences of viral toxicities and host immune response. Curr Cardiol Rep. 2020;22(5):32.

9. Ai T, Yang Z, Hou H, Zhan C, Chen C, Lv W, et al. Correlation of chest CT and RT-PCR testing in coronavirus disease 2019 (COVID-19) in China: a report of 1014 cases. Radiology. 2020;200642.

10. An P, Song P, Lian K, Wang Y. CT Manifestations of novel coronavirus pneumonia: a case report. Balkan Med J. 2020;37(3):1635.

11. Araujo-Filho JAB, Sawamura MVY, Costa AN, Cerri GG, Nomura CH. COVID-19 pneumonia: what is the role of imaging in diagnosis? J Bras Pneumol. 2020;46(2):e20200114.

12. Zhou Z, Guo D, Li C, Fang Z, Chen L, Yang R, et al. Coronavirus disease 2019: initial chest CT findings. Eur Radiol. 2020.

13. Zheng F, Tang W, Li H, Huang YX, Xie YL, Zhou ZG. Clinical characteristics of 161 cases of corona virus disease 2019 (COVID19) in Changsha. Eur Rev Med Pharmacol Sci. 2020;24(6):3404 10.

14.• Carey RM, Siragy HM. Newly recognized components of the renin-angiotensin system: potential roles in cardiovascular and renal regulation. Endocr Rev. 2003;24(3):261-71 This article focuses on the actions of RAS in circulation and in tissues. 
15. Kurtz A. Control of renin synthesis and secretion. Am J Hypertens. 2012;25(8):839-47.

16. D'Ardes D, Boccatonda A, Rossi I, Guagnano MT, Santilli F, Cipollone F, et al. COVID-19 and RAS: unravelling an unclear relationship. Int J Mol Sci. 2020;21(8).

17. Hamming I, Cooper ME, Haagmans BL, Hooper NM, Korstanje R, Osterhaus AD, et al. The emerging role of ACE2 in physiology and disease. J Pathol. 2007;212(1):1-11.

18. de Gasparo M, Catt KJ, Inagami T, Wright JW, Unger T. International union of pharmacology. XXIII. The angiotensin II receptors. Pharmacol Rev. 2000;52(3):415-72.

19. Ferrario CM, Jaiswal N, Yamamoto K, Diz DI, Schiavone MT. Hypertensive mechanisms and converting enzyme inhibitors. Clin Cardiol. 1991;14(8 Suppl 4):IV56-62 discussion IV83-90.

19•• Boehm M, Nabel EG. Angiotensin-converting enzyme 2-a new cardiac regulator. N Engl $\mathrm{J}$ Med. 2002;347(22):1795-7 This article discusses the role of ACE in blood pressure and the use of ACE inhibitors to lower blood pressure in patients with cardiovascular conditions and hypertension.

21. Reyes L, Hawkins CL, Rayner BS. Characterization of the cellular effects of myeloperoxidase-derived oxidants on H9c2 cardiac myoblasts. Arch Biochem Biophys. 2019;665:132-42.

22. Riquier-Brison ADM, Sipos A, Prokai A, Vargas SL, Toma L, Meer EJ, et al. The macula densa prorenin receptor is essential in renin release and blood pressure control. Am J Physiol Renal Physiol. 2018;315(3):F521-F34.

23.• Crackower MA, Sarao R, Oudit GY, Yagil C, Kozieradzki I, Scanga SE, et al. Angiotensin-converting enzyme 2 is an essential regulator of heart function. Nature. 2002;417(6891):822-8 This study indicates that a mutation on the $X$ chromosome of ACE2 is associted with severe heart defects in Rat models.

24. Rayner B, Jones E, Veriava Y, Seedat YK. South African Hypertension Society commentary on the American College of Cardiology/American Heart Association hypertension guidelines. Cardiovasc J Afr. 2019;30(3):184-7.

25. Campbell DJ. Circulating and tissue angiotensin systems. J Clin Invest. 1987;79(1):1-6.

26. Donoghue M, Hsieh F, Baronas E, Godbout K, Gosselin M, Stagliano N, et al. A novel angiotensin-converting enzyme-related carboxypeptidase (ACE2) converts angiotensin I to angiotensin 19. Circ Res. 2000;87(5):E1-9.

27. Tipnis SR, Hooper NM, Hyde R, Karran E, Christie G, Turner AJ. A human homolog of angiotensin-converting enzyme. Cloning and functional expression as a captopril-insensitive carboxypeptidase. J Biol Chem. 2000;275(43):33238-43.

28. Eriksson U, Danilczyk U, Penninger JM. Just the beginning: novel functions for angiotensin-converting enzymes. Curr Biol. 2002;12(21):R745-52.

29. Harmer D, Gilbert M, Borman R, Clark KL. Quantitative mRNA expression profiling of ACE 2, a novel homologue of angiotensin converting enzyme. FEBS Lett. 2002;532(1-2):107-10.

30. Hamming I, Timens W, Bulthuis ML, Lely AT, Navis G, van Goor H. Tissue distribution of ACE2 protein, the functional receptor for SARS coronavirus. A first step in understanding SARS pathogenesis. J Pathol. 2004;203(2):631-7.

31. Sanchis-Gomar F, Lavie CJ, Perez-Quilis C, Henry BM, Lippi G. Angiotensin-converting enzyme 2 and antihypertensives (angiotensin receptor blockers and angiotensin-converting enzyme inhibitors) in coronavirus disease 2019. Mayo Clin Proc. 2020;95(6): 1222-30.

32. Yan R, Zhang Y, Li Y, Xia L, Guo Y, Zhou Q. Structural basis for the recognition of SARS-CoV-2 by full-length human ACE2. Science. 2020;367(6485):1444-8.

33. Batlle D, Wysocki J, Satchell K. Soluble angiotensin-converting enzyme 2: a potential approach for coronavirus infection therapy? Clin Sci (Lond). 2020;134(5):543-5.
34. Turner AJ, Tipnis SR, Guy JL, Rice G, Hooper NM. ACEH/ACE2 is a novel mammalian metallocarboxypeptidase and a homologue of angiotensin-converting enzyme insensitive to ACE inhibitors. Can J Physiol Pharmacol. 2002;80(4):346-53.

35. Chappell MC. Emerging evidence for a functional angiotensinconverting enzyme 2-angiotensin-(1-7)-MAS receptor axis: more than regulation of blood pressure? Hypertension. 2007;50(4):5969.

36. Whelton PK, Williams B. The 2018 European Society of Cardiology/European Society of Hypertension and 2017 American College of Cardiology/American Heart Association blood pressure guidelines: more similar than different. JAMA. 2018;320(17):1749-50.

37. Seedat YK. Hypertension in black South Africans. J Hum Hypertens. 1999;13(2):96-103.

38. Unger T, Borghi C, Charchar F, Khan NA, Poulter NR, Prabhakaran D, et al. 2020 International Society of Hypertension global hypertension practice guidelines. Hypertension. 2020;75(6): 1334-57.

39. Busse LW, Chow JH, McCurdy MT, Khanna AK. COVID-19 and the RAAS-a potential role for angiotensin II? Crit Care. 2020;24(1): 136.

40. Aronson JK, Ferner RE. Drugs and the renin-angiotensin system in covid-19. BMJ. 2020;369:m1313.

41. Gurwitz D. Angiotensin receptor blockers as tentative SARS-CoV2 therapeutics. Drug Dev Res. 2020;81:537-40.

42.• Ferrario CM, Jessup J, Chappell MC, Averill DB, Brosnihan KB, Tallant EA, et al. Effect of angiotensin-converting enzyme inhibition and angiotensin II receptor blockers on cardiac angiotensinconverting enzyme 2. Circulation. 2005;111(20):2605-10 This study discusses the effects of ACE2 inhibitors and Ang II blockers on the the ACE2 gene activity, blood pressure regulation, and Ang (1-7).

43. Vaduganathan M, Vardeny O, Michel T, McMurray JJV, Pfeffer MA, Solomon SD. Renin-angiotensin-aldosterone system inhibitors in patients with Covid-19. N Engl J Med. 2020;382:1653-9.

44. Abassi Z, Assady S, Khoury EE, Heyman SN. Letter to the Editor: Angiotensin-converting enzyme 2: an ally or a Trojan horse? Implications to SARS-CoV-2-related cardiovascular complications. Am J Physiol Heart Circ Physiol. 2020;318(5):H1080-H3.

45. Patel AB, Verma A. COVID-19 and angiotensin-converting enzyme inhibitors and angiotensin receptor blockers: what is the evidence? JAMA. 2020

46. Esler M, Esler D. Can angiotensin receptor-blocking drugs perhaps be harmful in the COVID-19 pandemic? J Hypertens. 2020;38(5): 781-2.

47. Battistoni A, Volpe M. Might renin-angiotensin system blockers play a role in the COVID-19 pandemic? Eur Heart J Cardiovasc Pharmacother. 2020.

48. Alexandre J, Cracowski JL, Richard V, Bouhanick B, Drugs CwFSPT. Renin-angiotensin-aldosterone system and COVID-19 infection. Ann Endocrinol (Paris). 2020;81(2-3):63-7.

49. Zhang H, Baker A. Recombinant human ACE2: acing out angiotensin II in ARDS therapy. Crit Care. 2017;21(1):305.

50. Rossi GP, Sanga V, Barton M. Potential harmful effects of discontinuing ACE-inhibitors and ARBs in COVID-19 patients. Elife. 2020;9.

51. Kuster GM, Pfister O, Burkard T, Zhou Q, Twerenbold R, Haaf P, et al. SARS-CoV2: should inhibitors of the renin-angiotensin system be withdrawn in patients with COVID-19? Eur Heart J. 2020;41(19):1801-3.

52. Zhang P, Zhu L, Cai J, Lei F, Qin JJ, Xie J, et al. Association of inpatient use of angiotensin-converting enzyme inhibitors and angiotensin ii receptor blockers with mortality among patients with hypertension hospitalized with COVID-19. Circ Res. 2020;126(12):1671-81. 
53. Perico L, Benigni A, Remuzzi G. Should COVID-19 concern nephrologists? Why and to what extent? The emerging impasse of angiotensin blockade. Nephron. 2020:1-9.

54. Sommerstein R, Kochen MM, Messerli FH, Grani C. Coronavirus disease 2019 (COVID-19): do angiotensin-converting enzyme inhibitors/angiotensin receptor blockers have a biphasic effect? J Am Heart Assoc. 2020;9(7):e016509.

55. Williams B, Zhang Y. Hypertension, renin-angiotensin-aldosterone system inhibition, and COVID-19. Lancet. 2020;395(10238): 1671-3.

56. John TJ, John K. Renin-angiotensin-aldosterone system dysregulation and severe acute respiratory syndrome coronavirus 2 (SARSCoV-2) infection. Eur Heart J. 2020;41(22):2126-7.

57. Zhou P, Yang XL, Wang XG, Hu B, Zhang L, Zhang W, et al. A pneumonia outbreak associated with a new coronavirus of probable bat origin. Nature. 2020;579(7798):270-3 .

58. Cardiology ESo. Position statement of the ESC Council on Hypertension on ACE-inhibitors and angiotensin receptor blockers [cited 202013 March]. Available from: https://www.escardio.org/ Councils/Council-on-Hypertension-(CHT)/News/position-statementof-the-esc-council-on-hypertension-on-ace-inhibitors-and-ang.

59. HFSA/ACC/AHA. Statement addresses concerns re: using RAAS antagonists in COVID-19 2020 [cited 202030 August]. Available from: https://www.acc.org/latest-in-cardiology/articles/2020/03/17/ 08/59/hfsa-acc-aha-statement-addresses-concerns-re-using-raasantagonists-in-covid-19.

60. International Society of Hypertension. A statement from the International Society of Hypertension on COVID-19 2020. Available from: https://ish-world.com/news/a/A-statement-fromthe-International-Society-of-Hypertension-on-COVID-19/.

61. Cure E, Cumhur CM. Angiotensin-converting enzyme inhibitors and angiotensin receptor blockers may be harmful in patients with diabetes during COVID-19 pandemic. Diabetes Metab Syndr. 2020;14(4):349-50

62. Fang L, Karakiulakis G, Roth M. Are patients with hypertension and diabetes mellitus at increased risk for COVID-19 infection? Lancet Respir Med. 2020;8(4):e21.

63. Diaz JH. Hypothesis: angiotensin-converting enzyme inhibitors and angiotensin receptor blockers may increase the risk of severe COVID-19. J Travel Med. 2020;27.

64. Emilsson V, Gudmundsson EF, Aspelund T, Jonsson BG, Gudjonsson A, Launer LJ, et al. Antihypertensive medication uses and serum ACE2 levels: ACEIs/ARBs treatment does not raise serum levels of ACE2. medRxiv. 2020.

65. Sama IE, Ravera A, Santema BT, van Goor H, Ter Maaten JM, Cleland JGF, et al. Circulating plasma concentrations of angiotensin-converting enzyme 2 in men and women with heart failure and effects of renin-angiotensin-aldosterone inhibitors. Eur Heart J. 2020;41(19):1810-7.

66. Guo J, Huang Z, Lin L, Lv J. Coronavirus disease 2019 (COVID-19) and cardiovascular disease: a viewpoint on the potential influence of angiotensin-converting enzyme inhibitors/angiotensin receptor blockers on onset and severity of severe acute respiratory syndrome coronavirus 2 infection. J Am Heart Assoc. 2020;9(7):e016219.

67. Guo X, Zhu Y, Hong Y. Decreased mortality of COVID-19 with renin-angiotensin-aldosterone system inhibitors therapy in patients with hypertension: a meta-analysis. Hypertension. 2020;76:e13-4.

68. Danser AHJ, Epstein M, Batlle D. Renin-angiotensin system blockers and the COVID-19 pandemic: at present there is no evidence to abandon renin-angiotensin system blockers. Hypertension. 2020;75(6):1382-5.

69. Kai H, Kai M. Interactions of coronaviruses with ACE2, angiotensin II, and RAS inhibitors-lessons from available evidence and insights into COVID-19. Hypertens Res. 2020;43(7):648-54.
70. Verdecchia P, Cavallini C, Spanevello A, Angeli F. The pivotal link between ACE2 deficiency and SARS-CoV-2 infection. Eur J Intern Med. 2020;76:14-20.

71. Fang Y, Guo Z, Chai Y, Zhang H, Wang Z. 2019 Novel coronavirus, renin-angiotension system imbalance and coronavirus disease 2019. Zhonghua Wei Zhong Bing Ji Jiu Yi Xue. 2020;32(5):613-7.

72. Sriram K, Insel PA. Risks of ACE inhibitor and ARB usage in COVID-19: evaluating the evidence. Clin Pharmacol Ther. 2020;108:236-41.

73. Mehta N, Kalra A, Nowacki AS, Anjewierden S, Han Z, Bhat P, et al. Association of use of angiotensin-converting enzyme inhibitors and angiotensin ii receptor blockers with testing positive for coronavirus disease 2019 (COVID-19). JAMA Cardiol. 2020;5: 1020-6.

74. de Abajo FJ, Rodriguez-Martin S, Lerma V, Mejia-Abril G, Aguilar $\mathrm{M}$, Garcia-Luque A, et al. Use of renin-angiotensin-aldosterone system inhibitors and risk of COVID-19 requiring admission to hospital: a case-population study. Lancet. 2020;395(10238):170514.

75. Felice C, Nardin C, Di Tanna GL, Grossi U, Bernardi E, Scaldaferri $\mathrm{L}$, et al. Use of RAAS inhibitors and risk of clinical deterioration in COVID-19: results from an Italian cohort of 133 hypertensives. Am J Hypertens. 2020.

76. Yang G, Tan Z, Zhou L, Yang M, Peng L, Liu J, et al. Effects of ARBs and ACEIs on virus infection, inflammatory status and clinical outcomes in COVID-19 patients with hypertension: a single center retrospective study. Hypertension. 2020;76:51-8.

77. Khera R, Clark C, Lu Y, Guo Y, Ren S, Truax B, et al. Association of angiotensin-converting enzyme inhibitors and angiotensin receptor blockers with the risk of hospitalization and death in hypertensive patients with coronavirus disease-19. medRxiv. 2020.

78. Reynolds HR, Adhikari S, Pulgarin C, Troxel AB, Iturrate E, Johnson SB, et al. Renin-angiotensin-aldosterone system inhibitors and risk of Covid-19. N Engl J Med. 2020;382(25):2441-8.

79. Meng J, Xiao G, Zhang J, He X, Ou M, Bi J, et al. Reninangiotensin system inhibitors improve the clinical outcomes of COVID-19 patients with hypertension. Emerg Microbes Infect. 2020;9(1):757-60.

80. Bean DM, Kraljevic Z, Searle T, Bendayan R, Kevin OG, Pickles A, et al. ACE-inhibitors and Angiotensin-2 Receptor Blockers are not associated with severe SARS-COVID19 infection in a multisite UK acute Hospital Trust. Eur J Heart Fail. 2020;22:967-74.

81. Li J, Wang X, Chen J, Zhang H, Deng A. Association of reninangiotensin system inhibitors with severity or risk of death in patients with hypertension hospitalized for coronavirus disease 2019 (COVID-19) infection in Wuhan, China. JAMA Cardiol. 2020.

82. Peng YD, Meng K, Guan HQ, Leng L, Zhu RR, Wang BY, et al. Clinical characteristics and outcomes of 112 cardiovascular disease patients infected by 2019-nCoV. Zhonghua Xin Xue Guan Bing Za Zhi. 2020;48(0):E004.

83. Mancia G, Rea F, Ludergnani M, Apolone G, Corrao G. Reninangiotensin-aldosterone system blockers and the risk of Covid-19. N Engl J Med. 2020;382:2431-40.

84. Iaccarino G, Borghi C, Cicero AFG, Ferri C, Minuz P, Muiesan $\mathrm{ML}$, et al. Renin-angiotensin system inhibition in cardiovascular patients at the time of COVID19: much ado for nothing? A statement of activity from the Directors of the Board and the Scientific Directors of the Italian Society of Hypertension. High Blood Press Cardiovasc Prev. 2020;27(2):105-8.

Publisher's Note Springer Nature remains neutral with regard to jurisdictional claims in published maps and institutional affiliations. 